\title{
Family History and Its Influence on Infants' Language Development
}

\author{
Geetanjali Das*, Priya M. \\ Department of Human Development, Avinashilingam Institute for Home Science and Higher Education for Women-University, India
}

Copyright $(2017$ by authors, all rights reserved. Authors agree that this article remains permanently open access under the terms of the Creative Commons Attribution License 4.0 International License

\begin{abstract}
Infants' language development built upon a variety of experience. Language is commonly defined as an organized way of combining symbols in order to communicate. Parents and caretakers plays an important role in helping children learns to communicate, read and write. There is possibly no greater shift in development than the advancement of language abilities from birth to three. So in present study researcher had made an attempt to identify the language development from $0-2$ years. The study was undertaken in Coimbatore district with the total sample of 100 infants selected randomly in the age group 0-2 years and the researcher also interviewed their caretakers like parents, grandparents/aya whose age range from 22-65 years. The researcher framed self-prepared questionnaire to interview care takers as well as had observation of each child. The researcher contacted the infant's care takers and also made direct observation and collected information on how infants respond to their environment, family health status, home environment, care takers role, family type, number of children they have and quality of child care given. Researcher made observation on infants' responses to language or speech and child's abilities in language. From this study it has been found that there was a significant difference observed in infants' language development with respect to gender, number of children present in family, type of family and type of care taker. Family history and health status were less affected on female infants' language development compared to male infants. Whereas, child's age did not predict much influences on language development. Joint family children performed better language and social skills compared to nuclear and extended families. Even though mother and child interactions were more important for language development, children did better when they were along with the grandparents and parents. However when children brought up with helper/aya were not able to think, respond and communicate properly and also discovered they were slower in language abilities.
\end{abstract}

Keywords Family History, Language Development, Language Abilities

\section{Introduction}

Language is crucial to young children's development; it is the essential key for learning, communicating and building relationships with others as well as for enabling children to make sense for the world around them. The pattern of language milestones is very similar across the languages and appears to be similar for toddlers who are learning a second language (Erika Hoff, 2009; Barbara Newman, Philip Newman, 2008[4, 1]). There is possibly no greater shift in development than the advancement of language abilities from birth to three. While researchers disagree about the extent to which we come pre-wired to learn language, there is no dispute that the ability to learn to fluently speak one or more languages is a uniquely human ability that (barring another complication) we are all capable of doing. In fact, many of our babies are able to demonstrate a relatively advanced level of linguistic mastery with signs, or a combination of signs and words, by 12 months says Michelle Anthony in parent and child magazine. It has been empirically shown as early as 6 months to be associated with later receptive and expressive language skills (Morales, 2001[10]). Language development continues throughout the lifespan, the formative years occur in infancy and preschool when, through interaction with others, children discover the meanings of words, the way in which meaning is represented and the way in which language is used toward the purpose of communication. Parents and caregivers play an important role in helping children learn to communicate with others, and, eventually, to read and write. Parents want to do the best for their children, and need information in order to make choices and decisions about how they will parent, and what their priorities should be. Present research confirms the fundamental role that parents play as their child's first and most important teacher. The rate of development varies widely, however, depending both on the amount and nature of children's language experience and family history, health status, type of family and number of children present in 
family may have influence on child's language abilities. Keeping all these in view the following objectives were made.

\section{Objectives:}

- To observe Infants language development.

- To know the influence of family history and health status on infants language development.

- To assess primary, secondary and tertiary care taker's role on infant's language development.

\section{Hypothesis:}

- There is a significant difference on infants language development with respect to age, gender

- There is a significant difference among family history and health status on infants language development

- There is a significant difference among care takers role on infants language development

\section{Methodology}

The study was undertaken in Coimbatore district and the total sample of 100 infants selected randomly in the age group 0-2 years and the researcher also interviewed their caretakers like parents, grandparents/aya whose age range from 22-65 years. A random sample from each stratum is taken in a number proportional to the stratum's size when compared to the population. These subsets of the strata are then joining to form a random sample. The researcher framed self-prepared questionnaire (Annexure-I) to interview care takers as well as observed the child. The purpose of the study was explained to the parents/ grandparents/ care takers/ aya from different households where infants are reared. The care takers then approached according to their free timings to establish good rapport and to get related information. And also their infants were observed to know the level of language development by gestures and communication made with the researcher.

The statements include positive and negative factors. Positive statements will be scored as 3,2,1 and negative as 1, 2, 3 respectively. Higher the score better the language development and low score indicates problems with family history and other aspects.

\section{Ethical Clearance of the Study}

The application form explaining the design and the protocols used in the research study was subjected to the Institutional Human Ethics Committee (IHEC) and clearance was obtained. The approval ID for the study is AUW/IHEC/HD-15-16/XMT-01.

\section{Results and Discussion}

The total number of 100 infants and 100 care takers were taken as samples for the present study. This group consisted of infants, father, mother, grandparents and aya (nanny). Aya is an individual who doesn't belongs to a family but provides care for the child as a service. She has been appointed in some households to help mother/ when both parents are working.

The selected samples were distributed according to gender wise, age, number of children, family types and type of caretakers.

Table 1 illustrates the demographic profile of the selected samples.

The researcher selected the total 100 infants; among them $52.0 \%$ were male and $48.0 \%$ female infants.

Among selected samples, the infant's age range from upto 6 months, 7-12 months, 13-18 months, 19-24 months and their percentage were 15,33,13 and 39 respectively.

According to number of children in the family, each family consisted of different number of children. Thirty percent were having one child, 40 percent families have two children, 20 percent families having three children and rest 10 percent having more than three children in their family.

In excess of last 50 years' family type/structure has changed dramatically. A family is a group of people who live together to fulfill all basic needs. It has been categorized as nuclear, joint and extended. In present study, 42 percent belongs to nuclear family, 35 percent are from joint families and remaining 23 percent belongs to extended families.

In the selected samples it shows that due to change in working pattern and family structure now a day's families are depending on ayas/nanny for their child care. Even in the present study, we observe 47 percent families' infants were reared by grandparents, 41 percent infants were took care by their own parents and 12 percent families were depending on aya for child care. 
Table 1. Background information of the selected samples

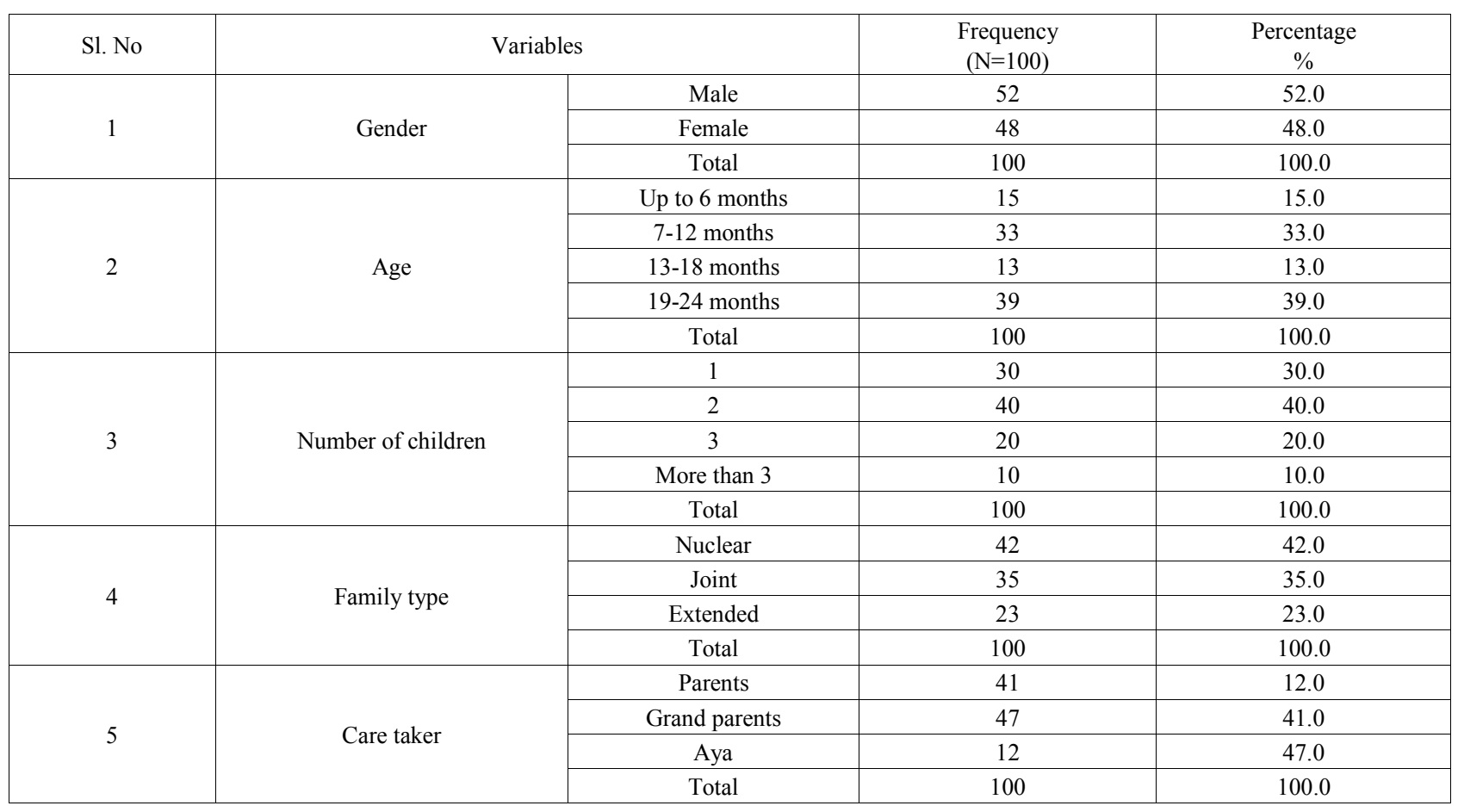

Table 2. Below and above average scores of family history and health status

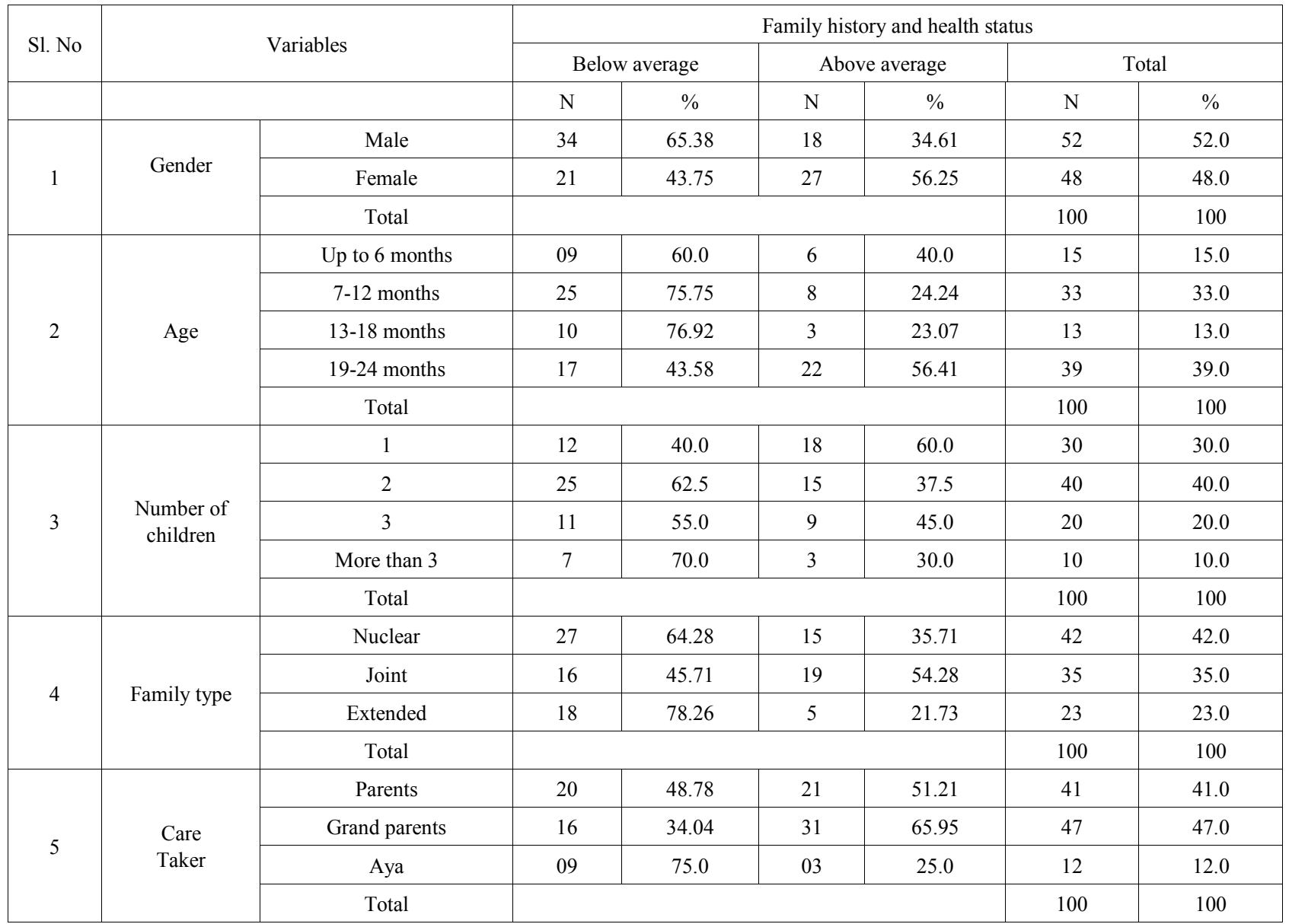


Table 3. Mean, $\mathrm{SD}$ and $\mathrm{t} / \mathrm{F}$ values of family history and health status in relation to infant's language development

\begin{tabular}{|c|c|c|c|c|c|}
\hline \multicolumn{6}{|c|}{ Family history and health status } \\
\hline Sl. No & Variables & $\mathrm{N}$ & Mean & SD & $t / F$ value \\
\hline & Gender & & & & \\
\hline 1 & Male & 52 & 16.78 & 2.17 & \multirow{2}{*}{$\begin{array}{c}\mathrm{t}=-2.055 \\
.043^{*}\end{array}$} \\
\hline \multirow[t]{2}{*}{2} & Female & 48 & 17.75 & 2.50 & \\
\hline & Age & & & & \\
\hline 1 & Up to 6 months & 15 & 17.40 & 1.95 & \multirow{4}{*}{$\begin{array}{c}\mathrm{F}=1.816 \\
.149^{\mathrm{NS}}\end{array}$} \\
\hline 2 & 7-12 months & 33 & 16.57 & 2.73 & \\
\hline 3 & $13-18$ months & 13 & 17.00 & 1.82 & \\
\hline \multirow[t]{2}{*}{4} & 19-24 months & 39 & 17.84 & 2.26 & \\
\hline & Number of children & & & & \\
\hline 1 & 1 & 30 & 17.06 & 1.91 & \multirow{4}{*}{$\begin{array}{c}\mathrm{F}=.742 \\
.530^{\mathrm{NS}}\end{array}$} \\
\hline 2 & 2 & 40 & 17.12 & 2.83 & \\
\hline 3 & 3 & 20 & 17.95 & 2.30 & \\
\hline \multirow[t]{2}{*}{4} & More than 3 & 10 & 16.90 & 1.66 & \\
\hline & Family type & & & & \\
\hline 1 & Nuclear & 42 & 17.52 & 2.43 & \multirow{3}{*}{$\begin{array}{c}\mathrm{F}=4.887 \\
.010^{* *}\end{array}$} \\
\hline 2 & Joint & 35 & 17.77 & 2.38 & \\
\hline \multirow[t]{2}{*}{3} & Extended & 23 & 15.95 & 2.03 & \\
\hline & Care taker & & & & \\
\hline 1 & Parents & 41 & 16.63 & 2.12 & \multirow{3}{*}{$\begin{array}{c}\mathrm{F}=4.771 \\
.011^{* *}\end{array}$} \\
\hline 2 & Grand parents & 47 & 18.09 & 2.52 & \\
\hline 3 & Aya & 12 & 16.05 & 2.05 & \\
\hline
\end{tabular}

*Significant at 0.05 level ** Significant at 0.01 level NS-Not significant

Table 2 describes the influence of family history and health status on infants' language development with respect to different variables. Above average and below average scores were taken to find out the high and low values among the selected samples in this area.

Majority of male infants i.e. 65.38 percent were falling under below average scores and rest 34.61 percent infants were coming under above average. In case of female infants, 56.25 percent were scored above average and 43.75 percent are coming under below average level. By these values we can say that majority of male infants were having low scores in family health status which has influence on language development. Comparatively female infants were less affected by family history and health status on their language development.

Infants who were aged up to 6 months scored 60.00 percent in below average and 40.00 percent scored above average and indicated health status of family will have influence on infants' language development. 7-12 months aged infants were scored 75.75 percent in below average and 24.24 percent in above average, which shows health status of family will have more influence on language development. Similarly, 13-18 months old infants were also in the same condition where 76.92 percent falling under below average and 23.07 percent scored above average. 19-24 months old infants were less affected by family health status in their language development. Among them, 56.41 percent scored above average and 43.58 percent scored below average.

The influence of family history and health status were analyzed based on the number of children in the family. The results found that one child families scored 60.0 percent in above average and 40.0 percent in below average. Two children families scored 62.5 percent below average and 37.5 percent above average. Three children families scored 55.0 percent below average and 45.0 percent above average. More than three children families scored 70.0 percent scored below average and 30.0 percent scored above average score. Overall by this table we can conclude that family history and 
health status will have influence on Infants' language development, in those more than three children and two children families were more affected than one child and three children.

From the above table, 64.2 percent nuclear families scored below average and 35.7 percent scored above average. 54.28 percent joint families scored above average and 45.7 percent scored below average. In case of extended families 78.26 percent scored below average and 21.7 percent scored above average. Overall we can say that extended families were more affected by family history followed by nuclear family by family history and health status on their Infants' language development than joint families. Joint families were less affected by family history and health status.

The researcher identified the influence of family history and health status on caretaker such as parents, grandparents and aya. 75.0 percent of aya scored below average and 25.0 percent of them scored above average. 48.7 parents show below average and 51.2 percent of them score above average. Among grandparents, 34.0 percent were under below average and remaining 65.95 percent in above average values.

From the above table we can conclude that parents and grandparents care have more positive impact on infants language development whereas infants reared by aya ensure ample problems with language development.

Table 3 shows influence of family history and health status on infants' language development with respect to different variables.

Among gender, the mean values of male and female infants were 16.78 and 17.75 respectively. The corresponding SD scores were 2.17 and 2.50. The "t" value ( $\mathrm{t}=-2.055$ with sig. 2-tailed $.043, \mathrm{P}<0.05)$ was significant. From these results it is inferred that male infants were more affected by family health status with their language development, whereas female infants were less affected in their language skills by family history since the obtained mean and SD scores are higher than the male infants. Eriksson et al (2012[5]) in their study also selected 0-2.6 years infants and the results showed that girls are slightly ahead of boys in early communicative gestures, in productive vocabulary, and in combining words. The difference increased with age. Boys were not found to be more variable than girls. Despite extensive variation in language skills between language communities, the difference between girls and boys remained.

From an early age, children exhibit sex differences in their verbal abilities, with girls exceeding boys in most aspects of verbal performance (Hyde \& Linn, 1988; Kimura, 1998[7]). Girls not only produce their first words (Maccoby, 1966[8]) and first sentences (Ramer, 1976[12]) at a younger age than boys, but they also have larger vocabularies (Huttenlocher, Haight, Bryk, Seltzer \& Lyons, 1991[6]) and use a greater variety of sentence types (Ramer, 1976[12]) in their early communications than boys of the same age.

In relation to the age, up to 6 month old infants scored the mean and SD values of 17.4 and 1.95 respectively. In case of 7-12 months old infants the mean value was 16.5 with corresponding SD value of 2.73. Among 13-18 months aged infants mean and SD values were 17.0 and 1.82 respectively. Similarly, 19-24 months old infants scored 17.84 mean value and $2.26 \mathrm{SD}$ values. The ' $\mathrm{F}$ ' value $(\mathrm{F}=1.816$, sig. 149$)$ was not significant. From this we found that there was no significant difference between infant's belonging to different age groups in family history and health status with respect to infant's language development.

When it comes to number of children in the family, the mean values of one child family, two children, three children were almost similar i.e. $17.06,17.12$ and 17.95 respectively with the SD scores of 1.91, 2.83 and 2.30. The mean and SD values of families with more than three children were 16.90 and 1.66. The ' $F$ ' value $(F=.742$, sig .530) was not significant. It indicates that family history and health status will not have influence on the number of children with their language development.

In case of family types, the mean scores of nuclear and joint families were 17.52 and 17.77 with SD values of 2.43 and 2.38 respectively. Among extended families the mean score was 15.95 with corresponding SD value 2.03. The ' $F$ ' value $(\mathrm{F}=4.887$, sig. $010, \mathrm{P}<0.01)$ was significant. It shows that infants from extended families were more affected by family history and health status in relation to infant's language development, whereas nuclear and joint family infants were less affected on their language development with family history and health status. To conclude infants performed better in language abilities when they were in joint families and in nuclear rather than extended.

Earlier researchers have long recognized that family structure shapes children's health and development (Demo and Cox 2000[3]). However there are limited researches available in impact of family type on child's language skills. Laxmi Devi (1998[13]) stated family structure is related to the rate of language acquisition, the larger the family the greater being the delay. This finding holds up across all social classes, although its effect is less among more affluent families. A possible explanation is that when there are many children around the general level of language is lower than when much of the talking is from adults.

When infants reared by parents, the observed mean value was 16.63 and SD was 2.12. When grandparents afford infant care, the observed mean and SD values were 18.09 and 2.52 respectively. When infants were under the control of aya, the obtained mean and SD values were 16.75 and 2.05 respectively. It revealed that from the family history, when aya taken care of the infant it was found to be a problem for the infant's language development. The ' $F$ ' value was $(\mathrm{F}=4.771$, Sig. $011, \mathrm{P}<0.001)$ significant. It shows that infants were benefited by parental care and grandparents care in their language acquisition to develop successfully with their family history and health status. But nanny/aya who focuses on child care receives less input in their language development. 
This result also supported by Rachel Pick [11] Children who get extra attention from parents, grandparents (or people who act as grand- parents to them) are likely to do better at school rather than other family member.

The child's communication environment is a more dominant predictor of early language than social background. In turn, language development at the age of two years predicts children's performance on entry to school. So, what the mother did (in terms of activities and interaction with her child), had (in terms of resources) and felt (in terms of feeling supported and sense of wellbeing) in the first two years of her child's life was shown to be important when children started school. Parents and grandparents give their babies and young child an advantage when they talk with them, read with them, listen to and respond to their babbles, gestures and words. More conversations increase the advantage for children in terms of their language development (Cathy Hamer, 2012 [2]).

\section{Summary and Conclusions}

In present study focused on "Family History and its influence on infants Language Development". A total of 100 samples were observed and interviewed for the age group 0-2 years infants and their care takers who's age range from 22-65 years. The researcher framed self-prepared questionnaire to interview care takers as well as had observation of each child. The collected data were assessed according to above average and below average based on their scorings. Further it can be subjected to statistical analysis using $t$ test and $\mathrm{F}$ test (ANOVA).

\subsection{Key Findings of the Study}

- There is no significant difference observed among infants age in terms of their language development with respect to family history.

- There is a significant difference observed among gender with respect to language acquisition. Result stated that female infants scored higher mean values compared to male infants and indicated that male infants were affected by family health status with their language development, whereas female infants were less affected in their language skills by family history.

- There is a significant difference observed among type of family on infants' language development. The mean scores of extended families were lower than nuclear and joint, which shows that infants from extended families were more affected by family history and health status in relation to infant's language development, whereas nuclear and joint family infants were less affected on their language development with family health status.

- However there is no significant difference observed among number of children in the family on infants' language development.

- There is a significant difference observed among care takers role on infants language development. When infant's taken care by aya/nanny receives less input in their language development. Whereas infant's nurtured by grandparents and parents receives more positive inputs and better outcomes in language development. 


\section{Annexure-I}

Avinashilingam Institute for Home Science and Higher Education for Women, University

Topic: "Family history and its influence on infants' language development"

\section{A. Child and Family Background}

1. Age

\begin{tabular}{|l|l|l|l|}
\hline 6 Months & 7-12 Months & $13-18$ Months & $19-24$ Months \\
\hline & & & \\
\hline
\end{tabular}

2. Birth Weight

\begin{tabular}{|l|l|l|l|}
\hline $2.4 \mathrm{~kg}$ & $3.4 \mathrm{~kg}$ & $4.5 \mathrm{~kg}$ & $4.6 \mathrm{~kg}$ \\
\hline & & & \\
\hline
\end{tabular}

3. Gender

\begin{tabular}{|c|c|}
\hline Male & Female \\
\hline & \\
\hline
\end{tabular}

4. Number of children

\begin{tabular}{|l|l|l|l|}
\hline 1 & 2 & 3 & 4 \\
\hline & & & \\
\hline
\end{tabular}

5. Family Pattern

Nuclear:

Joint:

Extended:

6. Working

Father only:

Mother only:

Both:

\section{B. Family History and Health Status}

1-Yes, 2-Sometimes, 3-No

\begin{tabular}{|c|c|c|c|c|}
\hline Sl. No & Statements & 1 & 2 & 3 \\
\hline 1. & Do you know about child development of milestones? & & & \\
\hline 2. & Father will spend more time with the child. & & & \\
\hline 3. & Mother will spend more time with the child. & & & \\
\hline 4. & Do you suffer from depression and anxiety? & & & \\
\hline 5. & Do you have on history of neglect or abuse? & & & \\
\hline 6. & Are you suffering from BP? & & & \\
\hline 7. & Do you send your child for whole day to preschool for childcare? & & & \\
\hline 8. & Aya will take care of the child? & & & \\
\hline 9. & Grandparents will spend more time with the child. & & & \\
\hline 10. & Siblings will spend more time with the child. & & & \\
\hline
\end{tabular}




\section{Roles}

\section{1-Yes, 2-Sometimes, 3-No}

\begin{tabular}{|c|c|c|c|c|}
\hline Sl. No & Statements & 1 & 2 & 3 \\
\hline 11. & Do you like to spend time with child always? & & & \\
\hline 12. & Do you spend more time for bathing baby? & & & \\
\hline 13. & Do you play with your child and have communication? & & & \\
\hline 14. & Do you like to have conversation with child quarries? & & & \\
\hline 15. & Do you like to have somebody for child care? & & & \\
\hline 16. & Do you often leave baby and go out? & & & \\
\hline 17. & Do you abuse child whenever you are angry? & & & \\
\hline 18. & Do you neglect child? & & & \\
\hline
\end{tabular}

\section{Child Abilities in Language}

\section{1-Yes, 2-Sometimes, 3-No}

\begin{tabular}{|c|c|c|c|c|}
\hline Sl. No & Statements & 1 & 2 & 3 \\
\hline 19. & $\begin{array}{l}\text { Is it easy for your family or friends to have a conversation with } \\
\text { your child? }\end{array}$ & & & \\
\hline 20. & $\begin{array}{l}\text { Are you satisfied with how your child speaks your mother } \\
\text { Tongue? }\end{array}$ & & & \\
\hline 21. & $\begin{array}{l}\text { Compared with other children of the same age, does your child have difficulty producing correct } \\
\text { sentences? }\end{array}$ & & & \\
\hline 22. & Did your child face Difficulty while learning the names of colours, people, letters etc? & & & \\
\hline 23. & Are you forcing your child to speak in English or Hindi? & & & \\
\hline 24. & $\begin{array}{l}\text { Did your child face Difficulty while finding words or explaining to other people, says: "the, the, } \\
\text { the ..."? }\end{array}$ & & & \\
\hline 25. & Did your child face Difficulty while explaining what he/she wants? & & & \\
\hline 26. & Did your child feel any Difficulty while speaking fluently without any breaks? & & & \\
\hline 27. & $\begin{array}{l}\text { Did your child feel difficulty while pronouncing complex words such as "electric", "screwdriver" } \\
\text { etc? }\end{array}$ & & & \\
\hline 28. & Has your child ever been hospitalized? & & & \\
\hline
\end{tabular}

\section{E. Observation}

\section{1-Yes, 2-Sometimes, 3-No}

\begin{tabular}{|c|c|c|c|c|}
\hline Sl. No & Statements & 1 & 2 & 3 \\
\hline 29. & Child calms down or smiles when spoken to. & & & \\
\hline 30. & When feeding, child starts or stops sucking in response to sound. & & & \\
\hline 31. & Child Coos and makes pleasure sounds. & & & \\
\hline 32. & Child follows sounds with his or her eyes. & & & \\
\hline 33. & Child notices toys that make sounds. & & & \\
\hline 34. & Child understands words for common items such as "milk," "sugar," or "fruits". & & & \\
\hline 35. & Child imitates different speech sounds. & & & \\
\hline 36. & Child enjoys simple stories, songs, and rhymes. & & & \\
\hline 37. & Child pays attention to sounds. & & & \\
\hline 38. & Knows a few parts of the body and can point to them when asked. & & & \\
\hline 39. & Speaks in a way that is understood by family members and friends & & & \\
\hline 40. & He/she wave when he hears bye bye. & & & \\
\hline 41. & $\mathrm{He} /$ she say mamma, dada as trying to talk. & & & \\
\hline 42. & Has a special way of crying for different needs. & & & \\
\hline 43. & Child delay to speak. & & & \\
\hline 44. & Child pronounces any word wrongly. & & & \\
\hline 45. & Child face any difficult to either to learn or writing. & & & \\
\hline
\end{tabular}




\section{F. Other Information}

1-Yes, 2-Sometimes, 3-No

\begin{tabular}{|c|l|l|l|}
\hline Sl. No & \multicolumn{1}{|c|}{ Statements } & \multicolumn{1}{|c|}{$\mathbf{3}$} & \multicolumn{1}{|c|}{$\mathbf{1}$} \\
\hline 46. & Has your child been evaluated by any other professional? & & \\
\hline 47. & Has your child had a previous speech-language evaluation? & & \\
\hline 48. & Did you child have any difficulties with Feeding, Sleeping, Bonding, Other? & & \\
\hline 49. & Does your child have any health issues? & & \\
\hline 50. & Does your child take any medication? & & \\
\hline
\end{tabular}

[6] Huttenlocher J, Haight W, Bryk A, Seltzer M, Lyons T. Early vocabulary growth: relation to language input and gender. Developmental Psychology. 1991; 27(20):236-248.

\section{REFERENCES}

[1] Barbara Newman, Philip Newman (2008), Development Through Life: A Psychosocial Approach, Cengage Learning, 0495553417,9780495553410

[2] Cathy Hamer (2012), Perspective - NCT's journal on preparing parents for birth and early parenthood, National Literacy Trust, US

[3] Demo and Cox. Journal of Marriage and Family, Vol. 62, Issue 4, Pp. 876-895, 2000.

[4] Erika Hoff (2009), Language Development at an Early Age: Learning Mechanisms and Outcomes from Birth to Five Years, McGill University, Canada

[5] Eriksson M, Marschik PB, Tulviste T, Almgren M, Pérez Pereira M, Wehberg S, Marjanovič-Umek L, Gayraud F, Kovacevic M, Gallego C.(2012), Differences between girls and boys in emerging language skills: evidence from 10 language communities, Br J Dev Psychol. 2012 Jun; 30(Pt 2):326-43. doi: 10.1111/j.2044-835X.2011.02042.x. Epub 2011 Jun 1.

[7] Hyde JS, Linn MC. Gender differences in verbal ability: a meta-analysis. Psychological Bulletin. 1988; 104(1):53-69.

[8] Maccoby E. The development of sex differences. Stanford University Press; Stanford, CA: 1966.

[9] Morales M, Mundy P, Rojas J. Following the direction of gaze and language development in 6-month-olds. Infant Behav Dev. 1998; 21(2):373-377.

[10] Morales M, Mundy P, Delgado CEF, et al. Responding to joint attention across the 6-through 24-month age period and early language acquisition. J Appl Dev Psychol. 2000; 21(3):283-298.

[11] Rachel Pick. Grandparents and the extended family, Leaflet of Understanding childhood Ltd, UK, 2014.

[12] Ramer ALH. Syntactic styles in emerging language. Journal of Child Language. 1976; 3: 49-62.

[13] Laxmi Devi (1998), Child Development an Introduction, Anmol Publications Private Ltd, New Delhi 